\title{
La normalidad del trabajo, empleos normales y vidas de trabajo: razones para trabajar
}

\author{
Estela Grassi \\ Universidad de Buenos Aires (UBA)
}

La normalidad del trabajo, empleos normales y vidas de trabajo: razones para trabajar

Resumen: ¿Cómo se trabaja y se vive hoy y qué razones nos motivan para hacerlo? El artículo presenta hipótesis al respecto, teniendo como referencia el empleo formalmente instituido, contemplado por la legislación laboral, modalidad que no agota el hecho de que la mayoría de las personas "vive de su trabajo", cualquiera sea la consideración que sus capacidades reciban.Se detiene en la idea de normalidad, distinguiendo entre el nivel de los principios estructurales (el trabajo como amalgama de la sociedad), de aquel que corresponde a la legalidad, que a su vez es desbordado por las normalidades de las vidas de trabajo. Retoma luego las "razones razonables" que esgrimimos las personas cuando tomamos decisiones respecto de nuestras vidas y trabajos concretos, como parte de las reconfiguraciones recientes en la esfera del trabajo, en la que destacan la mayor incertidumbre y la exigencia de mayor disponibilidad. En esa conjunción, los intereses-necesidades del sujeto, y las exigencias de aquella esfera se presentan como tensiones que las personas y familias deben resolver como "asuntos privados".

Palabras claves: trabajo, normalidad, normas/razones, necesidades familiares, carrera-interés.

\section{A normalidade do trabalho, empregos normais e vidas de trabalho: razões para trabalhar}

Resumo: Como se trabalha e se vive hoje, e que razões nos motivam a fazê-lo? O artigo apresenta hipóteses sobre o assunto, tendo como referência o emprego formalmente instituído, contemplado na legislação laboral, modalidade que não esgota o fato de a maioria das pessoas "viver do seu trabalho", qualquer que seja a consideração que se faça das suas capacidades. Focaliza a idéia de normalidade, distinguindo entre o nível dos princípios estruturais (o trabalho como amálgama da sociedade), e aquele que corresponde à legalidade, o qual, pela sua vez, é desdobrado pelas normalidades das vidas de trabalho. Na sequência, retoma as razões razoáveis que esgrimem as pessoas quando tomam decisões a respeito das suas vidas e trabalhos concretos, como parte das reconfigurações recentes da esfera de trabalho, na qual se destacam a maior incerteza e a exigência de maior disponibilidade. Nessa conjunção, os interesses-necessidades do sujeito e as exigências daquela esfera apresentam-se como tensões que as pessoas e as famílias devem resolver em termos de "assuntos privados".

Palavras-chave: trabalho, normalidade, normas/razões, necessidades familiares, carreira-interesse.

\section{The Normality of Labor, Normal Jobs and Working lives: Reasons to Work}

Abstract: How do people work and live today and what are the reasons that motivate doing so? This paper presents a hypothesis, using as a reference formally instituted employment, as determined by labor legislation, a modality that does not exhaust the fact that most people "live to work," regardless of the consideration that their abilities receive. It uses the idea of normality, distinguishing it from the level of the structural principals (work as an amalgam of society), from that which corresponds to legality, which in turn flows from the normalities of the lives of work. It looks at the "reasonable reasons" that people use when they make decisions about their concrete lives and work, in the context of the recent reconfigurations in the sphere of labor, highlighted by greater uncertainty and the demand for greater availability. In this situation, the interests and needs of the subject and the demands of that sphere are issues that people and families must resolve as "private issues."

Key words: labor, normality, norms/reasons, family needs, career-interest.

Recebido em 27.03.2009. Aprovado em 04.08.2009. 


\section{Presentación}

La idea de trabajo remite, en general, a las capacidades humanas potenciales de hacer actividades (labores), que radican simultáneamente en la mente y el cuerpo de las personas. Pero esas capacidades y actividades sólo existen como relaciones sociales históricas, puestas en acto en procesos sociales de producción, por lo que el trabajo no se define por ellas, sino por la relación social que hace que esas potenciales capacidades y actividades, devengan “trabajo". Más aún - si seguimos a Postone (2006, p. 214) - no se trata de que en el capitalismo, "el trabajo se realiza en el marco de relaciones sociales mercantiles", sino que él mismo (el trabajo capitalista en abstracto) es la "mediación social" que amalgama esta particular formación socio-histórica. Recién entonces (desde un punto de vista lógico), el trabajo concreto es históricamente determinado, en primer lugar, por la propia estructura de la mediación social (la forma mercancía de la fuerza de trabajo), y luego, por las condiciones del intercambio, que son contingentes y presentan una importante variabilidad, no solamente histórica, sino contemporáneamente, entre regiones, sectores de la economía, grupos sociales, etc. Por lo tanto, las capacidades concretas, así como la "utilidad" social de aquello a lo que se aplican no corresponden a una esencia humana general o a la naturaleza de ésta, sino que le viene dada por esa relación que configura una sociedad particular (el capitalismo moderno o la sociedad del trabajo $^{1}$ ). Y lo mismo sucede con el reconocimiento social del trabajador.

En términos de Polanyi (1992), la mercantilización del trabajo es una ficción porque "no fue creado para su intercambio"; podemos agregar que esto es así, además, porque la invención del trabajo como fuente de la riqueza y objeto de intercambio, requiere de un pase de prestidigitación ${ }^{2}$ del pensamiento que lo abstraiga de donde está, sin embargo, irremediablemente adherido: el cuerpo y la mente, necesariamente comprometidos ambos en las más elementales o complejas, o solitarias o cooperativas tareas. Pero "ficción" no es sinónimo de "falsedad", pues volviendo a Postone - no se trata de que la fuerza de trabajo es tratada como si fuera una mercancía, sino que esta condición es ya la relación (el principio estructural) a partir de la que se generan (o es habilitante de) las condiciones para que sus portadores (esos de los que es inalienable) se comporten como trabajadores; es decir, como agentes del mercado que disponen de una mercancía particular: capacidades laborales. Capacidades (habilidades, saberes) que se ponen en acto en procesos de trabajo que no son sólo "producción de bienes y servicios", sino reproducción incesante de la sociedad del trabajo. Esta interpretación nos impide considerar al trabajo como universal ahistórico, y al mismo tiempo nos da la pauta acerca de la génesis de esa atribución.

En cuanto a los problemas que se abordan en este artículo, corresponden a procesos socio-culturales en los que se fueron conformando y emergen nuevos modos de relación entre ámbitos a los que el propio capitalismo dio lugar y disoció: el mundo del trabajo y el mundo de la vida. Si el trabajo (en abstracto) es la amalgama con la que se ligaron los modos de vida en la modernidad capitalista, el mundo de la vida no es ajeno a la estructuración por el trabajo, ni constituye simplemente un espacio de relaciones subordinadas o de segundo orden respecto del mismo, sino parte de su dominio; es decir, el mundo de la vida en las "sociedades del trabajo". Hablamos entonces, de un "modo de vida en el que trabajo y vida" (sólo) se distinguen porque hay algo más que hacer en la vida que solamente trabajar. No obstante, el despliegue de esos otros haceres posibles y necesarios (más o menos creativos) está fuertemente constreñido por la posibilidad y las condiciones del trabajo y lo que este mundo "ofrece" como y para una vida deseable. Por esta razón, las preguntas acerca de esa articulación cobran validez en circunstancias en las que uno y otro de estos ámbitos cambian significativamente.

¿Cómo se trabaja y se vive hoy (o cómo se vive y se trabaja)? El artículo contiene reflexiones que se derivan de las investigaciones que lleva adelante un grupo perteneciente al Instituto Gino Germani de la Facultad de Ciencias Sociales de la Universidad de Buenos Aires, que recientemente plasmó en un libro de elaboración colectiva (GRASSI; DANANI, 2009). Toma en consideración lo que "razonan acerca de lo que les acontece", quienes habitan una parte del mundo del trabajo: la del "empleo normal y protegido", formalmente instituido. Este enunciado requiere algunas aclaraciones. En primer lugar, esos "razonamientos" no son las respuestas a la pregunta; más bien, ellos contienen los datos, variables y modos de interpretar los acontecimientos de la vida que alimentan nuestra inquietud y hacen pertinente la pregunta. En segundo lugar, "mundo del trabajo" expresa nada más que el supuesto de que, bajo distintas modalidades, la mayoría de las personas vive de su trabajo y forma parte de él, cualquiera sea la valoración, reconocimiento o consideración que sus capacidades reciban. En ese mundo, la definición de trabajo normal, formalmente regulado, comprende los empleos por tiempo indeterminado, según jornadas regulares, con derecho a vacaciones y licencias pagas, y a un décimo tercer sueldo (aguinaldo) y cuyos agentes están comprendidos por la seguridad social, entre las principales condiciones establecidas por la ley de contrato de trabajo. En términos del ámbito o espacio socio-económico, nuestras observaciones se acotan a la región de Argentina más integrada al sistema mundial, dicho esto también en términos socio- 
culturales en general: la Ciudad de Buenos Aires y el Conurbano bonaerense. Estas precisiones deben desestimar cualquier expectativa de generalización empírica. No obstante, la intención es generar nuevas hipótesis acerca de las características del último ciclo de transformaciones del trabajo.

\section{El trabajo capitalista: la normalidad del trabajo y el empleo normal}

Antes de seguir, debemos detenernos en la idea misma de normalidad, para dejar sentado desde el principio que, cualquiera sea el ámbito "normalizado", ese resultado es histórico y, en nuestras sociedades, es la realización de alguna hegemonía. En consecuencia, toda normalidad es perecedera y está sujeta a los avatares de las luchas, interpretaciones y acciones de actores diversos. No obstante, hay un nivel de la normalidad que corresponde a los "principios estructurales" ${ }^{\text {y }}$ que se vive como natural, en cuyo caso su historicidad se reconstruye y aprehende por un esfuerzo de la investigación y el pensamiento, pues queda fuera de la experiencia y de la memoria histórica de la vida corriente porque el sujeto es constituido ya en los principios que perfilan un tipo de formación socio-cultural, lo que habilita su condición de agente reflexivo de la misma (GIDDENS, 1995a, p. 61). En ese nivel de la normalidad se inscribe la práctica concreta y específica de "trabajar" para el caso de las sociedades del trabajo que alumbró la modernidad capitalista, práctica cuya estabilización que llevó siglos y que trastocó profundamente los modos de vida pre-existentes. Es decir, aquella amalgama de la sociedad es el sustrato de esta "normalidad naturalizada" (y, como decíamos, la génesis de la esencialización del trabajo y de su representación como un universal abstracto, también por la teoría social).

En cambio, un horizonte más cercano a la experiencia histórica es el de la normalización del trabajo regular, a la que corresponde - y contribuye - la distinción/relación de la ocupación y del desempleo, como estados posibles alternativos de esa misma normalidad que, a su vez, se constituye en referencia de lo que "merece llamarse trabajo" y de lo que quedará fuera de tal definición. En otros términos, el trabajo regular y protegido define por oposición a la "informalidad laboral", y por negación a "la exclusión" del trabajo.

Sin embargo, es precisamente en la precariedad y contingencia de esta normalidad donde se inscriben los antagonismos que la mantienen en jaque, incluidos los desacuerdos entre quienes pretendemos interpretarla, definirla, caracterizarla y organizarla en categorías estadísticas y sociológicas (ocupación, desocupación, empleo precario, informal, changas, etc.). Presentadas como reflejo o interpretaciones más o menos ajustadas a "la realidad", tales categorías se imbrican en los procesos en los que ciertas condiciones devendrán (o no) normales, o quedarán expulsadas de lo que así se considere e instituya. Es decir, van entrelazadas en los procesos de normalización, que incluyen la producción de categorías de percepción y clasificación. Las instituciones del trabajo (desde los ministerios a los sindicatos) y la legislación laboral pueden entenderse, a su vez, como dispositivos de consagración por el Estado - la instancia máxima de consagración en nuestras sociedades - de lo que se tiene por normal y en relación con lo cual se juzga lo correcto (ajustado a la norma) o se castiga lo incorrecto (lo que se hace por fuera de la norma), determinación que habilita la protección de quien es o puede ser perjudicado por la acción trasgresora. De ahí que, se supone, la norma contiene una definición taxativa que cambia solamente cuando se cambia la norma.

Ahora bien, no por normada por el Estado se trata de una normalidad indiscutida: la trasgresión tan amplia y reiterada de las normas laborales es plena evidencia de que se la mantienen en jaque. La trasgresión es, en realidad, forma de la disputa en el proceso de configuración de alguna nueva normalidad; y el debate acerca de las normas o por la instauración o reforma de las instituciones del trabajo, participa de dicho proceso. Asimismo, si la ley delimita un estado de normalidad, no agota las "normalidades" posibles, ni aquellas concretas de las vidas de trabajo. Estas últimas corresponden a otro nivel de la cuestión, en el que se inscriben las preguntas que nos formulamos precedentemente: ¿cómo se vive y se trabaja hoy día? Si trabajar se impone como el normal quehacer de cada vida adulta, esto no significa siempre de la misma manera, ni para todos por igual.

\section{Contexto y reconfiguración reciente del mundo del trabajo}

Buena parte de la investigación referida a lo social durante la última década se llevó a cabo bajo el supuesto de la heterogeneidad. Los "nuevos pobres", los "nuevos ricos", los pobres y los ricos de siempre, los que ganaron y los que perdieron, los exitosos y los inempleables, los protegidos y los precarizados, los asalariados ocultos, los desocupados ocultos, los desocupados a secas, los que ascendieron socialmente y aquellos a los que, estando en eso, les cambiaron de lugar la escalera sin que alcanzaran a advertirlo, son los términos con los que reconocemos que la sociedad no es lo que era 20 años atrás, y las clases sociales no son lo que eran (o como creíamos que eran). Ese diagnóstico de heterogeneidad suele estar referido, a la vez, a un único universo, sean los pobres, los excluidos o los marginados, perdiéndose de 
vista la dinámica de la configuración de las diferencias y eventuales agrupamientos. Si la investigación puso sobre el tapete la variabilidad de situaciones, experiencias e intereses y ayudó a conocer sus particularidades, a la larga - al focalizarse reiteradamente en los mismos sectores con problemas o excluidos del trabajo como si fuera todo el universo de lo estudiable - condujo a reconstruir un supuesto implícito de homogeneidad de orden superior, que parece envolver a "los heterogéneos", hasta transformarlos en "otros diversos" - de distinta naturaleza - y autoreproducidos, fuera del espacio social. Estos enfoques desatienden los lugares, medios $\mathrm{y}$ agencias que determinan el eventual exceso o ineptitud de una cantidad o tipo de capacidades, lo que a su vez inhabilita a sus agentes.

Desde las primeras investigaciones en el campo de las políticas sociales llevadas a cabo por nuestro equipo, incorporamos la cuestión de las condiciones de trabajo como un eje central para comprender el significado de la privatización de algunos servicios y prestaciones sociales, la asistencialización de otros tantos, la focalización en "los pobres" de siempre y las compensaciones para los "nuevos pobres". Advertíamos entonces que esas transformaciones en estos sectores de políticas daban cuenta (y participaban) de la estructuración de nuevas instituciones y de cambios culturales que iban dando forma a la sociedad, más allá de las normas que lograban plasmarse. Simultáneamente se instalaba el "problema del desempleo", porque efectivamente al terminar el siglo 20 aumentó extraordinariamente el número de personas con problemas de trabajo (por estar efectivamente desempleadas, por estar subocupadas o sobreocupadas, u ocupadas en condiciones indeseables, etc.); y porque se construyó como el principal argumento (y amenaza) para impulsar reformas en las leyes e instituciones laborales que fragilizaron los lazos contractuales (las primeras) y desprotegieron a los trabajadores (las de seguridad social, principalmente). La "modernización" de las relaciones laborales fue convertida entonces en un objetivo, en una necesidad y en una solución a "los problemas del trabajo".

Los resultados agregados son conocidos: además del desempleo y la pérdida de la seguridad social, una desigualdad más marcada es, en realidad, el signo de la época. No obstante, no son estos los problemas en los que queremos hacer hincapié, sino en los procesos político-culturales en los que se inscribe lo que se da en llamar "la modernización de la relaciones laborales" y las "nuevas formas de gestión y organización del trabajo", con la advertencia de que no se trata de la aplicación ineludible y universal de modelos dados, sino más bien recursos en la disputa por el control del trabajo, cuyos resultados prácticos no son unívocos ni totalmente controlados, sino que los procesos siguen senderos posibles, a la medida de cada contexto: local, regional, de sector económico, etc. La "modernización de las relaciones laborales" no "modernizó" de la misma manera a todas las economías ni a todos los sectores, ni se flexibilizaron en un mismo sentido todos los empleos; y aunque es posible advertir que, en términos generales, se crearon condiciones para una mayor disponibilidad de la vida al trabajo, ésta no parece suponer mayor compromiso y menos aún, fidelidad del empleado. Por sobre todos los esfuerzos por ignorarlo o suprimirlo, la "gestión del trabajo" implica, en última instancia, lidiar con agentes, cuya condición fundamental es la capacidad de "acción reflexiva", condición que está lejos de limitarse a la "acción racional". En consecuencia, la metamorfosis del trabajo no puede expresarse únicamente en las prácticas en el interior de las unidades económicas, sino también en las circunstancias que justifican y motivan los esfuerzos, desvelos y denuedos de la mayoría de las personas. Justamente en estas circunstancias se empalma el mundo del trabajo y el mundo de la vida, al menos si aceptamos que "trabajamos por alguna/s buena/s razón/es" y no inopinadamente "para otros o para el capital", como zombis, forzados o por engaños.

\section{Razones para trabajar (1)}

Esas condiciones de disponibilidad y las exigencias que las reproducen, hacen pertinente escudriñar, entonces, en cómo se vive. Los hechos y sucesos comprendidos en los procesos que captamos como cambios sociales o culturales cobran sentido para el sujeto desde lo que para él es un mundo singular, y es en relación con esos sentidos que se toman decisiones y desarrollan acciones referidas "al trabajo". De modo que las "razones" por las que trabajamos encuentran su justificación en esta esfera de la vida. Ahí se halla la "razonabilidad" (BOURDIEU, 2001, p. 22) de trabajar por el propio interés o para no morirse de hambre, o de no emplearse para no perder el derecho al subsidio de la asistencia. Estas diversas "razones razonables" no son mera adaptación a posteriori a los cambios que se presentan en la esfera del trabajo o a las necesidades del mercado, ni siquiera a las de la sobrevivencia, sino que se inscriben en el universo de experiencias de sujetos cuya condición de trabajadores no está dada por la inmediatez de su empleo, sino por la propiedad de su relación con aquella esfera del trabajo y el mercado respectivo. Pero, a la vez, esa condición no agota la subjetividad ni constriñe la totalidad de la experiencia. Precisa- 
mente, de la división "fuerza de trabajo y trabajador" - escisión sobre la que se instituyó el capitalismo, abriendo así la posibilidad a la preservación de un tiempo y un espacio de la vida fuera del trabajo -, emergen los problemas de disciplina para trabajar y de gestión del personal, imposibles de resolver de una vez para siempre. Ya desde el mercantilismo la cuestión se planteó tanto en términos económicos como morales; entonces, el estado de necesidad permanente se concibió como la condición indispensable para asegurar una oferta de trabajo constante (además, de bajo costo), al obligar a trabajar a quienes de otro modo serían presa de la ociosidad, según la interpretación de esos pensadores y que nunca perdiera totalmente vigencia (DIEZ, 2001). Pero "trabajar" también se entendió como un "deber" - el de aportar a la riqueza de la nación , y como un medio de mejora moral de las clases bajas. No obstante, el solo esfuerzo y la sola obligación no siempre fueron convincentes ni eficientes. Así lo advirtieron quienes supusieron la natural racionalidad de los comportamientos humanos: precisamente por eso se requerirían otros estímulos que impulsaran a la gente a trabajar por su propio interés. La ampliación del consumo y la posibilidad de mejoras en las condiciones de vida de las clases trabajadoras constituyeron el corazón de la estrategia fordista, aunque la iniciativa de H. Ford reconoce una larga historia de construcción de la idea que asocia la disposición y la disciplina para trabajar, con las expectativas de progreso (de "salir adelante", de "asegurar el futuro de los hijos" o de "hacer una carrera", como es de uso en el lenguaje corriente). Como en los albores del capitalismo, aunque con menos crudeza, los discursos sobre la gestión del trabajo y la empleabilidad, sobre la integración social, y los de las políticas sociales, llevan implícita la cuestión de cómo asegurar que la gente trabaje y lo haga con la mayor eficiencia. En las últimas décadas, las estrategias ideológicas desplegadas en la problematización de las condiciones y disposiciones para el trabajo por agencias y agentes diversos, van por esos caminos trillados, oscilando entre el mantenimiento del estado de necesidad como impulso para trabajar y los estímulos de un consumo cada vez más sofisticado. Si el estímulo al consumo es un ingrediente siempre presente en nuestra cultura, y aquel más sofisticado puede ser un incentivo para quienes se emplean en sectores de la economía donde se requiere alta capacitación y se espera mayor disponibilidad, la concepción que sostiene el estado de necesidad como una forma de moralización se pone de manifiesto de manera inequívoca cuando se trata de los grupos más desprotegidos y cada vez que se discuten políticas sociales para "aliviar" o "compensar" las situaciones de pobreza ${ }^{4}$.
Razones para trabajar (2): la vida, la carrera, los afectos y... el tiempo

¿Qué razones "razonables" tenemos y esgrimimos los sujetos cuando tomamos decisiones respecto de nuestros trabajos concretos y cómo se entrama (y distingue, simultáneamente) la vida y el trabajo? Ahondando en el problema de cómo se trabaja de maneras más o menos compatibles con los tipos y niveles de compromiso y fidelidad requeridos en circunstancias históricas dadas, desde el lugar y la perspectiva del trabajador-persona, se halla que la normalidad de la vida de trabajo conlleva más tensiones que funcionalidad, no obstante que éstas se tratan y resuelven como problemas privados.

Con los debidos resguardos metodológicos (que no podemos desarrollar acá), simplificando la cuestión en un figurado continuum, la responsabilidad por sí y por otros (la familia, los hijos), y la realización de la carrera y el desarrollo profesional, ponen fuertemente en tensión la vida y la conciencia de personas "que viven de su trabajo" aunque sus condiciones de existencia sean muy disímiles. Es esa tensión la que interesa traer a la reflexión, porque precisamente se inscribe en un entramado de agencias y dispositivos (y, en consecuencia, de disposiciones) sociales que, aún negándose o contraponiéndose entre sí, son igualmente constituyentes de 'lo que somos' y, por lo tanto, igualmente verdaderas (social e históricamente hablando, hay que reafirmarlo, aunque resulte reiterado). En ese sentido, la separación trabajo/vida; producción/reproducción - diferenciación de ámbitos que se enraíza en el "principio de libertad" de las personas que organiza la vida corriente -, presupone la trama (no "evidente") en la que "vida y reproducción" son inmediatamente condiciones y requisitos de la sociedad (de su existencia como comunidad política y sistema económico). Relación a la que equivale la obligación-necesidad de trabajar $\mathrm{y}$ los derechos que preservan la posibilidad y las condiciones para hacerlo. No obstante, en la objetivación de la esfera del trabajo, y en la preservación de la vida privada del sujeto, se halla también la génesis de la relegación de esta última a una consideración secundaria respecto del trabajo, y de la subjetivación de las necesidades. "Fuera del trabajo... arreglate tu vida" es la expresión de ese menoscabo en palabras de una joven empleada, por comparación con su situación presente, que juzga de "buena suerte".

Para ella, "tener una vida" comprende estudiar, estar con sus afectos, distraerse un poco, aquello que el trabajo parece sustraerle y echan de menos muchos otros, dándole razón a su apreciación. El bienestar o el disfrute futuro, el progreso personal y la carrera, o la familia y los hijos, justifican, en diferentes medidas, el sacrificio cotidiano del goce presente, de los afectos 
familiares y de la compañía de los hijos porque el trabajo se impone a estas dimensiones de la existencia ordinaria, en teoría, ajenas a esa esfera. "Cuestiones privadas" que, por eso, tienen escasa consideración en los objetivos y en la gestión del trabajo, fuera del cual, como dice esta joven, "arreglate tu vida".

Paralelamente, no es el mejoramiento de aquello que se hace "en el trabajo" lo que mayormente es esgrimido como la razón de los desvelos de las personas entrevistadas ${ }^{5}$, sino que la eventual eficiencia parece, más bien, subordinarse efectivamente al "propio interés";; o la necesidad y el temor ${ }^{7}$. Ahora bien, la tensión producida entre aquella regla de "arreglate tu vida" y las de la carrera personal o la necesidad imperiosa, se "resuelve" por una notable inversión de tiempo de vida de las personas, que se resta a aquello que, luego, se hecha de menos (o se espera compensar en el futuro): la compañía de la pareja, el acompañamiento de los hijos, las celebraciones familiares... los afectos, en fin. Si en otros tiempos los novios tenían acotados sus encuentros amorosos porque la familia pautaba los días y horarios de visita, hoy nadie se interpone en la relación y la convivencia es una práctica habitual, tanto como la incorporación de las mujeres al mercado de trabajo. Liberados de prejuicios y en condiciones de entera libertad para el ejercicio de la sexualidad, las constricciones son invisibles, porque (para algunos grupos) derivan de la libertad de elegir por el trabajo que absorbe el tiempo de ambos. En los ámbitos más competitivos, "es muy difícil criar una familia y llevar este ritmo de trabajo", porque tampoco hay nuevas redes o instituciones que asuman aquello que "antes hacía la familia". Allí, entonces, es posible que "en algún momento... las mujeres den un paso al costado".

Como contraste, al final de ese continuum simplificado, no hay una carrera por delante, pero sí obligaciones presentes y entonces son las "necesidades de la familia" las únicas que se ofrecen como razones del esfuerzo y, a su vez, estas necesidades marcan los límites de las decisiones que se toman en materia laboral (no faltarle el respeto al trabajo).

Referente a mí, no es que me molesta, lo único que me llama la atención, no es que me llama la atención, o sea el tema de los chicos...entendés? Con la gorda más o menos. O sea, es una chica grande, [así se refiere a la esposa] más o menos lo entiende, pero con el tema de los chicos a veces noto... me parece extraño, porque de pronto considero que no tienen tanto apego a mí... Vos por ahí hasta podés llegar a pensar 'Y la mami, nunca se preocupó por explicarle papá no está porque está trabajando para que nosotros podamos estar en las condiciones que estamos, que podamos estar tranquilos, etc, etc.?'¿ entendés?...
Quien así se manifiesta es un padre de familia de edad mediana, cuyas calificaciones y habilidades no encuentran más demandas que en nichos acotados que están mal pagos y son poco valorados. La mujer de este hombre trabaja y él desearía que no lo hiciera, aunque sabe de las necesidades de su hogar, pero también de lo que llama "las evoluciones". Es decir, que "una mujer que se preparó igual que nosotros, tuvo una expectativa de vida" no puede dedicarse solamente a la casa. Es de los que quedaron en el medio de un proceso que trasciende largamente al trabajo, en el que los varones perdieron la condición de proveedores, y con ello, la autoridad que esa condición les daba en la familia. En ese mismo proceso ganó su condición de ser sensible, que le hace desear las expresiones de afecto de sus hijos. Pero las necesidades de su hogar y su fuerte compromiso con una vida mejor para su descendencia, lo transforman en un padre ausente, casi un extraño en un hogar en el que está muy poco tiempo. Ya no es el padre proveedor, ni el marido autoritario, pero tampoco puede ser el dador del afecto que las nuevas representaciones familiares incentivan. Esa familia de los afectos y la privacidad requiere ciertas condiciones, como disponibilidad de tiempo, y una vivienda que no sea solamente abrigo de la intemperie. Para y por la familia (en aras de un futuro mejor para los hijos) se sacrifica el tiempo, con la ilusión de que se lo invierte trabajando, aunque trabajo y familia se hagan incompatibles cuando el tiempo tiempo de vida - está casi todo disponible como tiempo de y para el trabajo.

La modernidad capitalista alumbró un modo de vida con el que se constituyó un sujeto autoválido, capaz de asegurarse su subsistencia, de progresar y/o ser reconocido por su participación en el ámbito de la producción que, dijimos, se presenta ajena a las relaciones sociales directas (POSTONE, 2006, p. 240); es decir, aquellas de donde pueden derivarse los significados de las prácticas, entre ellas, "trabajar". La normalización de la familia como el lugar de los afectos se acompañó de un sentido de responsabilidad por su cuidado que extendió hasta ella la autovalía, en primer lugar del varón. Precisamente la autoridad del padre de familia se sostuvo en su condición de proveedor, que le daba, a su vez, las razones para trabajar. Esa normalidad creada por infinidad de dispositivos no hace menos real el sentimiento de responsabilidad, amor y de cuidados que mueve a sus miembros ${ }^{8}$.

Desde nuestros orígenes de la Argentina como Nación se alentó esa moral familiar, y hoy las corrientes liberalizadoras de las costumbres también alimentan nuestros sentidos de felicidad y responsabilidad familiar, aunque diversos paradigmas proponen distintos ideales y patrones de comportamiento que no siempre son enteramente discernibles ni compatibles. Tener y mantener a los hijos, cuidarlos, educarlos, criarlos en 
un clima de afecto, comprensión y diálogo, son principios de una larga historia de constitución y transformaciones de la familia (de normalizaciones diversas o sucesivas) que incluye su democratización y la liberalización de sus lazos. Es también la fuente que alimenta la culpabilización privada por los problemas sociales de todo orden (la delincuencia, la drogadependencia, la desescolarización, etc.). Hoy puede decirse que en el interior de la familia se redistribuyó la responsabilidad por el mantenimiento (por lo tanto, la obligación de trabajar) y consecuentemente, la autoridad, así como viró el carácter de los vínculos, redistribuyéndose la responsabilidad/ necesidad de los afectos y el sentido de los mismos. Asimismo, la felicidad (propia y/o la de la descendencia) se halla, en nuestro medio y en nuestro tiempo, política y culturalmente constituida como una necesidad vital que constituye y que se impone, incluso, como exigencia para el sujeto ${ }^{9}$. Exigencia de su entera responsabilidad; también en este sentido es libre y autónomo.

Pero al menos en parte el cumplimiento de estas responsabilidades depende de la realización de la autovalía, de su inclusión en el trabajo en primer lugar, $\mathrm{y}$ de las condiciones de pertenencia en cada espacio particular. Pertenencia necesaria, pero no suficiente de bienestar y felicidad; y aún necesaria y contrapuesta, al mismo tiempo. En la opción entre dignidad/éxito y felicidad, ésta se relega a un segundo plano porque "estar fuera del trabajo" es ya negación de la felicidad, aunque "estar dentro" sea un impedimento, si no queda tiempo "para tener una vida", ser reconocido por los propios hijos o "criar una familia".

En esa exigencia de autovalía así extendida (por sí y por la familia), y en la voluntad y capacidad de sostenerla se funda, entonces, la pertenencia y la dignidad del sujeto: nadie más que cada uno es dueño de su destino y es el trabajo el medio que evita caer en la tutela y la dependencia. Sin embargo, es en la objetividad de la esfera del trabajo (de la producción) donde las capacidades concretas (saberes, habilidades y capacidades) de sujetos concretos pierden su condición de tal para ser, simplemente, trabajo en tanto factor de la producción: aquí el destino se escapa de las manos.

Sin embargo, "autovalía y voluntad" mantienen una fuerte asociación en la composición de las prácticas, de tal modo que no poder mantenerse (incluyendo a la familia) y/o progresar por el trabajo es fuente de descrédito e indignidad. Aunque estos términos no necesariamente tienen los mismos contenidos ni se asocian a las mismas expectativas, la impronta de la voluntad, y la presentación de las decisiones laborales/ vitales como disyuntivas de las personas, están presentes como denominadores comunes. El sujeto se encuentra solo ante decisiones que son privadas en el sentido estricto de que son "su problema", "problemas privados".

\section{La emergencia de una nueva normalidad}

La relación trabajo-vida permite explorar las "normalidades de la normalidad" y adentrarse en las lógicas y ritmos diversos del "cómo se trabaja", que engendra también una dinámica de vida en la que se retroalimenta. Como señalamos, la autovalía por la participación en el trabajo, libre de dependencias y tutelas, constituye lo nuclear de la normalidad en relación con la cual nos reconocemos y reconocemos a los demás: ganarse la vida por el trabajo es, a su vez, la ratificación de que esta es la forma de estar en el mundo ${ }^{10}$. Ahora bien, las regulaciones legales que paulatinamente limitaron la disposición de la fuerza de trabajo hicieron posible, para el trabajador, una vida fuera del trabajo (la vida familiar) que tuvo a la mujer como principal protagonista. La representación de la familia trabajadora o de la familia obrera incluía un tiempo en el hogar preservado por la normalidad de la jornada legal, servicios sociales para el cuidado de la prole (guarderías, colonias de vacaciones), "beneficios sociales" ofrecidos por el sindicato (hoteles para vacacionar, clubes y centros deportivos y de esparcimiento para la familia), entre otros recursos. Seguridad social y servicios sociales que, sin haber sido concebidos con alcance universal en el caso de Argentina, formaron parte de la normalidad de la vida de trabajo que incluía la preservación de la vida familiar (aunque también la domesticidad de las mujeres). Ciertamente, los procesos culturales desde los años 60 cambiaron la fisonomía de la vida familiar, y las sucesivas crisis, de la década del 70 en adelante, pusieron en jaque aquella representación, pero sobre 
todo, la seguridad y las normas que la preservaban. Dos procesos sucesivos se dieron a lo largo del último cuarto del siglo XX: la fragmentación del mercado de trabajo, que al final dejó fuera de la seguridad social a casi la mitad de la población trabajadora; y el cuestionamiento de la validez y de la legitimidad de las instituciones protectoras y de la seguridad social $\mathrm{y}$ - fundamentalmente - de los principios de responsabilidad colectiva (política, por lo tanto). Aquello que se había estabilizado a mediados del siglo pasado, se deshizo al final del mismo, cuando la estabilidad y la seguridad - la previsibilidad, en suma -, fueron las condiciones a ser desterradas del ámbito del trabajo para ser transferidas a la performance del sujeto en el trabajo. Entonces se transformó aquello que parecía un círculo virtuoso y funcional: vida familiar-trabajo.

Si la vida social no existe fuera de la trama de normas y de las normalidades - dadas en primer lugar y de manera mediata, por los principios estructurales - que, a su vez, se despliegan en configuraciones culturales múltiples, híbridas y heterogéneas, esa multiplicidad de configuraciones parece hilvanarse hoy con los hilos de la deslegitimación de las pretensiones de certidumbre frente a la eventualidad de quedar fuera del trabajo, de la radicalización de la individuación y también, de la modernización y democratización de los lazos familiares.

En síntesis, en este ciclo ¿qué se lleva el trabajo? Aquello que la propia modernidad permitió inventar como valioso cuando el mundo se secularizó y el hombre empezó a hallar en su propia vida las razones por la que ésta merecía ser vivida. Como muestra Giddens (1995b), los lazos parentales, de amistad, de pareja, etc. pudieron "deseconomizarse" con la mayor individuación y cuando la esfera del trabajo se afirmó como medio de vida ${ }^{11}$. Sin olvidar el papel que le cabe a la familia en la reproducción de la fuerza de trabajo, es igualmente atendible la interpretación de Giddens en el sentido de que estas relaciones pudieron volverse (relativamente) “desinteresadas" entonces, y más aún con el desarrollo de los sistemas previsionales y de seguridad social, que contribuyeron a hacer menos dependiente al individuo de la familia y de las relaciones primarias en general. Con ellos, los hijos dejaron de ser un reaseguro para la vejez de los padres, y la relación filial fue adquiriendo un nuevo significado, según el cual la felicidad futura de la prole pasó a depender de la calidad de los cuidados y afectos de los progenitores. Pero el cultivo de estos lazos requiere de aquello que, hoy más intensa y prioritariamente, se aplica al trabajo - tiempo -, cuyo transcurso y medida se desprendió del mundo de la vida y cuya organización, por eso, escapa al control de las personas, más inflexiblemente cuando los acuerdos político-normativos se debilitan. La normatividad ju- rídica expresa el sentido que tiene el tiempo en la producción moderna, y regula su disposición, preservando un espacio para la sociabilidad y el descanso. Pero la normalidad más allá de las normas muestra un tiempo cooptado por el trabajo, sea por la necesidad de aumentar ingresos escasos, por temor a perder el empleo, por las opacas y cambiantes reglas de juego de la competencia y de la carrera, y también porque las condiciones del medio urbano hacen que se consuma improductivamente una porción variable del mismo, que es a pura pérdida del sujeto.

En resumen, el tiempo concreto del que se dispone para los miembros de la familia de cuya felicidad y bienestar se es responsable, es limitado y constreñido por el trabajo, sean cuales sean las razones y condiciones en las que se trabaja y aún cuando una parte del mismo suele (debe) hacerse "por la familia" y en la búsqueda de su bienestar.

La nueva normalidad tejida con aquellos cambios ocurridos en el tránsito a este siglo rebasa las normas del empleo formal, que ya no son suficiente reaseguro frente al riesgo de quedar fuera de la normalidad, sea de ganarse la vida por el trabajo, o de labrarse una carrera y progresar. Ambos imperativos configuran también, qué duda cabe, vidas y normalidades diferentes, pero que tienen en común un tiempo cooptado por el trabajo, y un panorama incierto.

\section{Referencias}

BOURDIEU, P. Las estructuras sociales de la economía. Buenos Aires: Manantial, 2001.

DIEZ, F. Utilidad, deseo y virtud. La formación de la idea moderna del trabajo. Barcelona: Península, 2001.

GIDDENS, A. La constitución de la sociedad. Bases para la teoría de la estructuración. Buenos Aires: Amorrortu, 1995a.

La transformación de la intimidad. Sexualidad, amor y erotismo en las sociedades modernas. Madrid: Cátedra, 1995b.

GRASSI, E.; DANANI, C. (Org.). El mundo del trabajo y los caminos de la vida. Trabajar para vivir; vivir para trabajar. Buenos Aires: Espacio Editorial, 2009.

OFFE, C. Trabalho \& Sociedade. Problemas estruturais e perspectivas para o futuro da sociedade do trabalho. Rio de Janeiro: Tempo brasileiro, 1989. (v. I).

POLANYI, K. La gran transformación. Los orígenes políticos y económicos de nuestro tiempo. México: Fondo de Cultura Económica, 1992. 
POSTONE, M. Tiempo, trabajo y dominación social. Una reinterpretación de la teoría crítica de Marx. Madrid: Marcial Pons, 2006.

\section{Notas}

1 Según Offe (1989, p. 13-14) la expresión fue acuñada por Dahrendorf(1980). Se refiere a la sociedad burguesa volcada a la actividad económica, dedicada al trabajo, impulsada por su racionalidad y atravesada por los conflictos del trabajo que, a su vez, han sido el objeto de indagación de la teoría social, de Marx, Durkheim a Weber.

2 El sentido figurado de esta expresión no hace a la cuestión menos real. Pretende enfatizar que el trabajo no se comprende por ninguna evidencia, si no por un esfuerzo para reconstruir la relación más allá de lo evidente.

3 Principio de organización de totalidades societarias; factores que intervienen en el acondicionamiento general institucional de una sociedad o tipo de sociedad (GIDDENS, 1995a, p. 54/397).

4 Los subsidios y planes sociales para desocupados concitan los mayores señalamientos acerca de sus efectos desestimulantes para los trabajadores y hasta el propio seguro por desempleo tiene sus detractores que bregan por limitarlo "para que la gente quiera volver a trabajar".

5 Para todos los depoimentos registrados fue solicitado el consentimiento libre y esclarecido de los sujetos entrevistados, a partir de un término de consentimiento para publicación, debidamente firmado por el investigado e investigador. Se aseguró la confidencialidad y privacidad de sus declaraciones, garantizando la no utilización de la información en perjuicio de los que participaran de la investigación y se observaron las normas legales y éticas para la investigación que envuelve seres humanos.

6 "Vas mirando un poco, cómo venís de edad y como viene tu carrera, vas viendo para acomodarte en el mejor plazo posible de la mejor manera. Si te vas todos los días a las seis (fin de la jornada normal), pareciera como muy evidente que tenés menos carga laboral que los otros. Y eso en algún momento, alguien lo va a notar."

7 "Ya estoy grande, qué se yo...no voy a ponerme a distraerme, por faltarle el respeto al laburo es muy posible que en cualquier momento me llame el jefe y me diga - Mire Fulano... acá se necesita efectividad permanente...”

8 Esta "realidad" de los afectos familiares no niega la realidad de las tensiones y conflictos que fuera destacada por la crítica intelectual y política a la idea de una Familia a-histórica y naturalizada.
9 Si tradicionalmente la "buena familia" remitía al abolengo, hoy se espera "contención afectiva".

10 Salvo para quienes son socialmente dispensados de la obligación de trabajar, dispensa que comprende a distintos grupos, por diferentes razones, según los momentos y contextos históricos.

11 Se trata de una posibilidad, no de un camino ineludible, por lo que no puede afirmarse más que en general, mientras que se hallan diferencias tanto culturales como sociales.

\section{Estela Grassi}

egrassi@mail.fsoc.uba.ar

Doctora en Ciencias Antropológicas

Licenciada en Trabajo Social

Profesora Titular Regular en la Carrera de Trabajo Social

Facultad de Ciencias Sociales da Universidad de Buenos Aires (UBA)

Investigadora en el Instituto Gino Germani y Directora del Grupo de Estudio sobre Políticas Sociales y Condiciones de Trabajo de ese Instituto

\section{Universidad de Buenos Aires (UBA)}

Presidente J. E. Uriburu $950-6^{\circ}$ Piso (CP. 1114)

Buenos Aires - Argentina 